\title{
Image Processing for Save Life Predictions of Tomato Fruit using RGB Method
}

\author{
Aristoteles \\ Computer Science Dept. \\ Lampung Of University \\ Lampung - Indonesia
}

\author{
Ossy Dwi Endah W \\ Computer Science Dept. \\ Lampung Of University \\ Lampung - Indonesia
}

\author{
Dwi Susanto \\ Computer Science Dept. \\ Lampung Of University \\ Lampung - Indonesia
}

\begin{abstract}
Tomatoes are agricultural commodities has the high consumption for Indonesian people. Tomato fruit shave different shape and color, the color of a tomato can characterize the level of maturity. This research has been determine the level of maturity of tomatoes based on the color. The simulcast tomatoes for counting levels of tomato color image using a digital camera. Image color of Tomato levels obtained by calculating the average value of RGB components of the tomatoes picture. The red color more than 60 percent (ripe) indicates shelf life 7-10 days, the red color more than 40 percent (half-ripe tomatoes) indicates shelf life 10-12 days, the red color more than 20 percent (half-unripe tomatoes) indicates shelf life 1315 days, and the red color less than 20 percent (unripe tomatoes) over 15 days. This research shows the levels of red and green color affect the level ripeness of tomatoes. The higher the red colors and decreasing green color of fruit tomatoes indicate tomatoes more ripened. The position of tomatoes simulcast affect the level of accuracy, when tomatoes simulcast from the side reached accuracy 100 percent, while from the top reached 62.5 percent.
\end{abstract}

\section{Keywords:}

Clasifications, Image Processing, Maturity, Save, Tomato, RGB

\section{INTRODUCTION}

Tomatoes easily damaged agricultural commodities, we need scheduling tomatoes crop for maintained quality. One way for maintained quality by expect at field. The problem for estimate tomato self life in several varieties of hard by farmers.

Image processing technique has been conducted for determine the ripeness of tomatoes [1] [3] [4] [5]. Levels of red and green colors used to determinate of the level of ripeness [4] [5], tomatoes ripening divided into 3 classes: unripe, half ripe, and ripe [3][4][5]. Picture taken form top and sides of tomatoes [5]. Other research has using hue values to determine level of tomatoes ripeness[1].

This research design of software can determine level of tomatoes ripeness and self life prediction tomatoes based on picture. Tomatoes picture obtained be processed using image processing.

This research focus on analysis tomatoes shelf life based on colors, tomatoes color analyse use RGB algorithm, and tomatoes analyse only one tomato each time.

\section{METHODOLOGY}

The stage of this research on Fig.1.

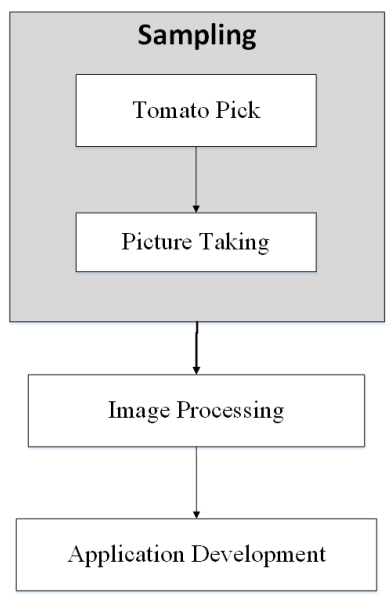

Fig. 1. Step of research.

\subsection{Sampling}

Sample taken by random tomatoes. Tomato fruit picked and take picture is 40 . The picture taken with fixed distance, different positions, camera and lighting remain.

\subsection{Image Processing}

Image processing in this research calculation of rgb color levels by this function[5]

$$
r=\frac{R}{R+G+B}
$$

where: $r=$ levels of red; $R=$ average red color on picture; $G=$ average green color on picture; $\mathrm{B}=$ average blue color on picture

$$
g=\frac{G}{R+G+B}
$$


where: $\mathrm{g}=$ levels of green; $\mathrm{R}=$ average red color on picture; $\mathrm{G}=$ average green color on picture; $\mathrm{B}=$ average blue color on picture

$$
b=\frac{B}{R+G+B}
$$

where: $b=$ levels of blue; $R=$ average red color on picture; $G=$ average green color on picture; $\mathrm{B}=$ average blue color on picture

Colour average image obtain from this formula [6]

$R=\frac{\sum_{i=1}^{n} \sum_{j}^{m} R_{i j}}{n . m} ; G=\frac{\sum_{i=1}^{n} \sum_{j}^{m} G_{i j}}{n . m} ; B=\frac{\sum_{i=1}^{n} \sum_{j}^{m} B_{i j}}{n . m}$

where: (1) i,j = position of pixel; (2) $\mathrm{m} \times \mathrm{n}=$ pixel size; (3) $R_{i} j=$ red color value at pixel i,j; (4) $G_{i} j=$ green color value at pixel $\mathrm{i}, \mathrm{j}$; and (5) $B_{i} j=$ blue color value at pixel i,j.

\subsection{Method}

This research adapt Unified Process Methodology [7] Fig.2

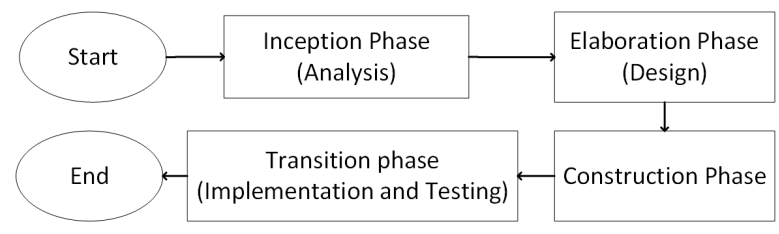

Fig. 2. Method from this research

\subsection{Application Design}

Software development needed (1) can analyse ripeness of tomato, (2) application can be analyse shelf life tomato, (3) analyse shelf life tomatoes with improvement of image and without improve of image.

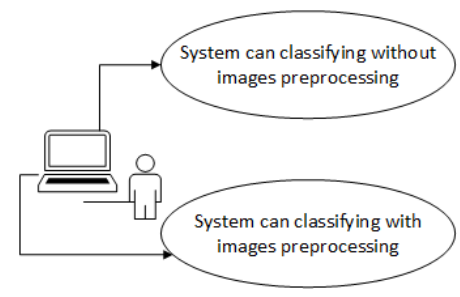

Fig. 3. Class Diagram from analysis.

State diagram for tomatoes image without preprocessing can look at Fig.4 and State diagram for tomatoes image with preprocessing can look at Fig.5

\subsection{Application Diagram}

Application diagram from development software on Fig. 6

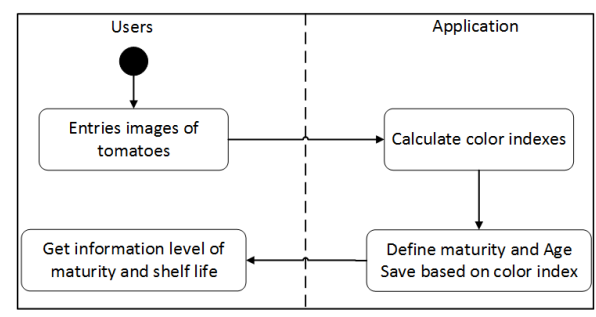

Fig. 4. State diagram without preprocessing.

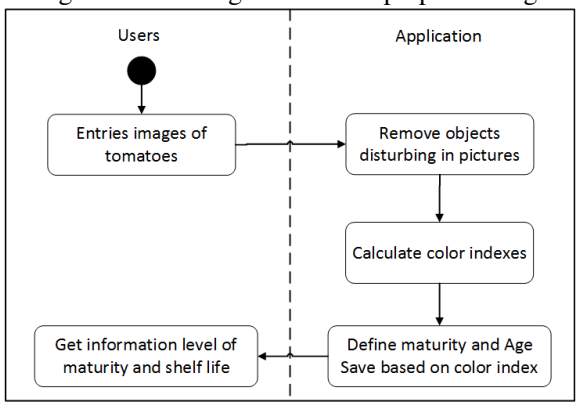

Fig. 5. State diagram with preprocessing.

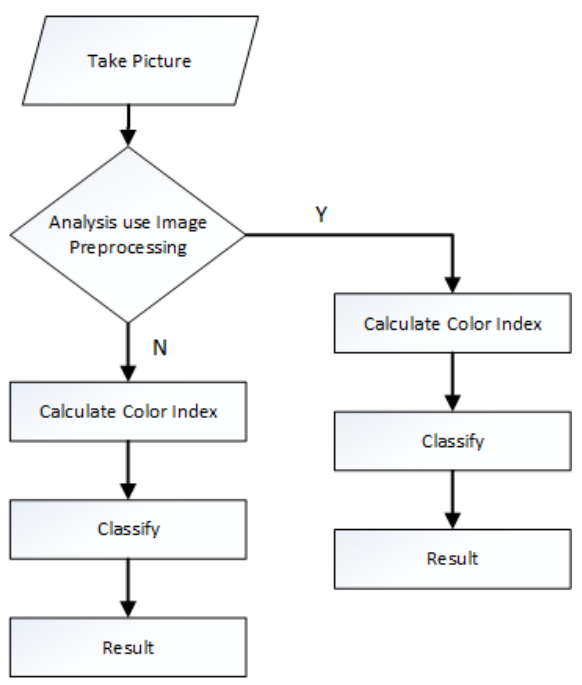

Fig. 6. Application Diagram

\section{DETERMINE THE CLASSIFICATION}

\subsection{Manual Classification}

Tomatoes classification based on manually classification level of ripening on Fig.7:

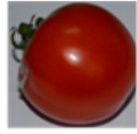

Ripe

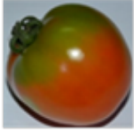

Half-ripe

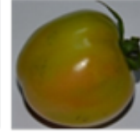

Half-Unripe

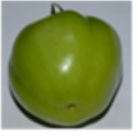

Unripe
Fig. 7. Ripening Tomatoes Level Manually 


\subsection{Without Improvements}

Data of tomatoes after taken picture calculated on classes Red and

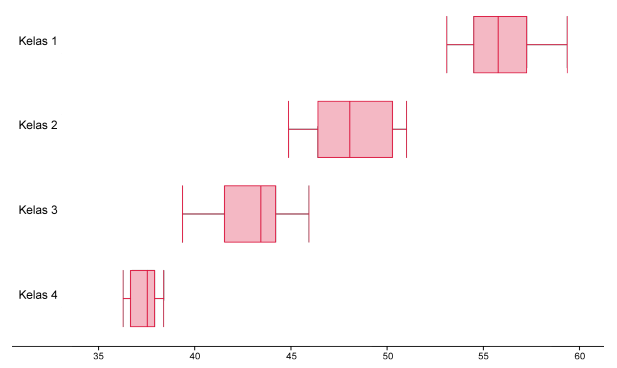

Fig. 8. Red Color Level Tomatoes Image Without Preprocessing.

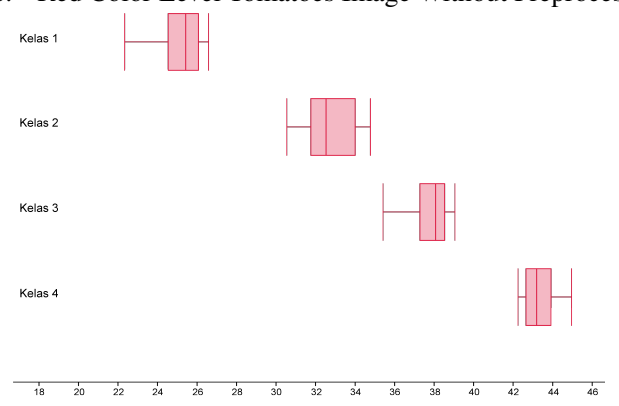

Fig. 9. Green Color Level Tomatoes Image Without Preprocessing.

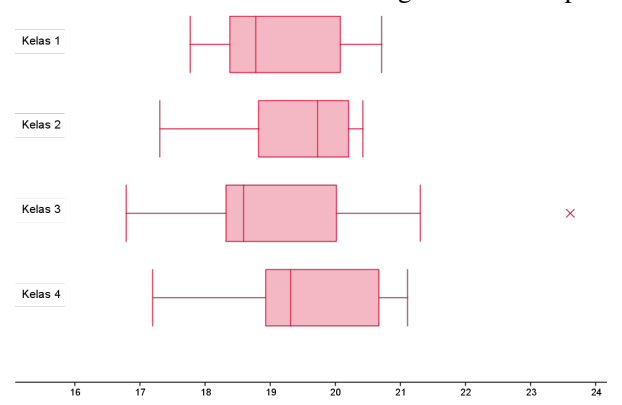

Fig. 10. Blue Color Level Tomatoes Image Without Preprocessing.

green color levels to each other is inversely proportional. blue color collide with each other can be seen between classes with each other and can therefore not be known boundary between minimum and maximum values from the data. difference of colors red and green between class 1 , class 2 , class 3 and class 4 can be seen based graphics served in the Fig. 8 and Fig. 9 difference of their blue color in Fig. 10, so that would not known different colors of class 1, class 2 , class 3 and class 4 .

Data rate levels of experimental data, minimum value and a maximum that is meant to facilitate the classification restrictions, that is, as follows:

Class 1 , the color red more than 44 percent and the green color less than 35 percent.

Class 2 (red tinge), the color red more than 44 percent and the green color less than 35 percent.

Class 3 (red tinge little), the color red over 39 percent and the green color less than 39 percent.
Class 4 (Raw), the color red less than 39 percent and the green color over 42 percent.

\subsection{Improving Images}

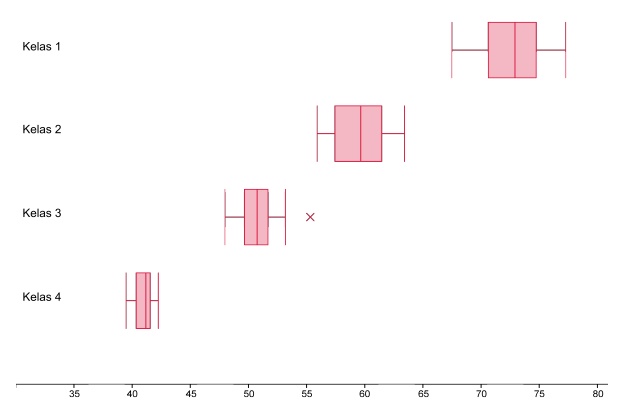

Fig. 11. Red Color Level Tomatoes Image With Preprocessing.

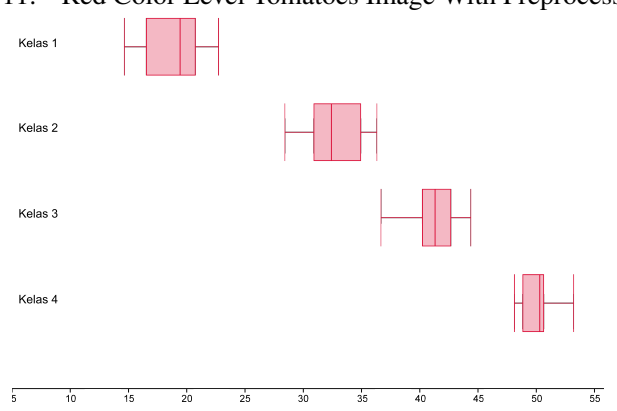

Fig. 12. Green Color Level Tomatoes Image With Preprocessing.

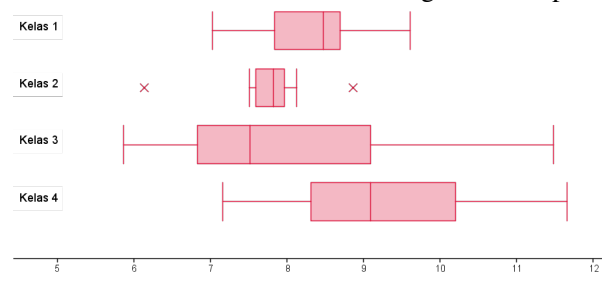

Fig. 13. Blue Color Level Tomatoes Image With Preprocessing.

Based on the data with and without using improving the image, there had been a difference that is quite significant. levels in every color component slightly shrinking when compared with the data before improving the image this leads to the occurrence of. classification differences between use and without using improving the image each tomato fruit that is observed in experiment was To classify a high degree of maturity tomato can be classified according the level red and green color, where and when tomato more mature red tomato levels will be more than. The green color for tomato that more mature tends to be more decreased, while for the blue color is not seen constant changes that can be seen in the Fig.13, the level of blue color samples relies on each other in every class, both class 1 , class 2 , class 3 and class 4 .

Constraints that used in classification overripe tomatoes based on the level their maturity can be done by using improving the image have limitations below:

Class 1 (ripe), the color red more than 67 percent and the green color less than 23 percent. 
Class 2 (half ripe), the color red more than 55 percent and the green color less than 28 percent.

Class 3 (half unripe), the color red more than 47 percent and the green color less than 45 percent.

While Class 4 (unripe), the color red less than 42 percent and the green color above 45 percent from the object that is observed tomato.

\section{APPLICATION}

Application was development can be look Fig. 14-16.

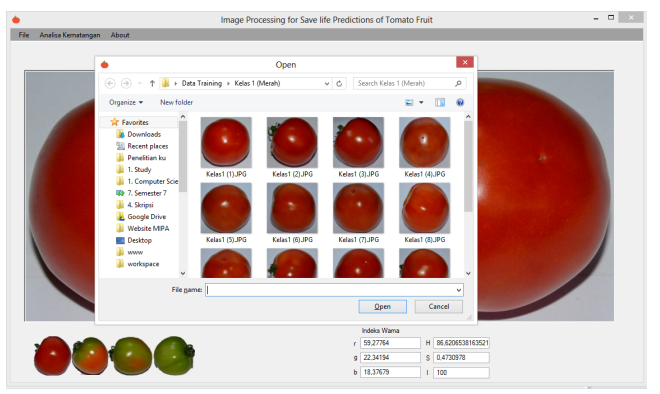

Fig. 14. System when opening picture

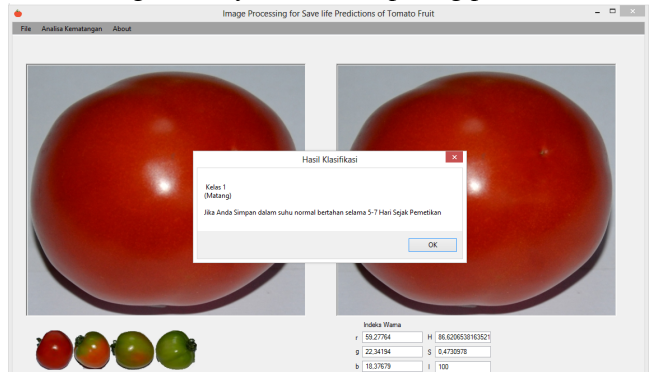

Fig. 15. System Analyzes without repair image

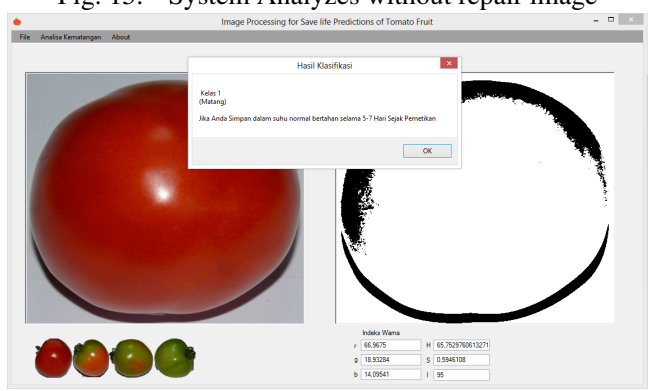

Fig. 16. System Analyzes with repair image

\section{TESTING}

Testing was done by provide input in the form of difference images, then calculate the level of ripening and age save and compare level of ripening tomatoes.
Table 1. Testing Result

\begin{tabular}{|c|c|c|c|c|}
\hline Data & Manual & Without & used Processing & Camera Position \\
\hline 1 & Class 1 & True & True & Side \\
\hline 2 & Class 1 & True & True & Side \\
\hline 3 & Class 1 & False & True & Side \\
\hline 4 & Class 1 & False & True & Side \\
\hline 5 & Class 1 & False & True & Side \\
\hline 6 & Class 1 & True & True & Side \\
\hline 7 & Class 2 & True & True & Side \\
\hline 8 & Class 2 & True & True & Side \\
\hline 9 & Class 2 & True & True & Side \\
\hline 10 & Class 3 & True & True & Side \\
\hline 11 & Class 2 & True & True & Side \\
\hline 12 & Class 2 & True & True & Side \\
\hline 13 & Class 3 & True & True & Side \\
\hline 14 & Class 4 & True & True & Side \\
\hline 15 & Class 4 & True & True & Side \\
\hline 16 & Class 4 & True & True & Side \\
\hline 17 & Class 3 & True & True & Top \\
\hline 18 & Class 3 & False & True & Top \\
\hline 19 & Class 3 & False & True & Top \\
\hline 20 & Class 1 & False & False & Top \\
\hline 21 & Class 1 & False & False & Top \\
\hline 22 & Class 1 & False & False & Top \\
\hline 23 & Class 4 & Error & True & Top \\
\hline 24 & Class 4 & Error & True & Top \\
\hline
\end{tabular}

\section{CONCLUSION}

Level of red color and green color can be used to determine the level of maturity tomatoes. The relationship between level of maturity and self life of tomatoes can determine levels of red color and green color of tomatoes. Classification can $58.33 \%$ level of accuracy before improve image and after improve images can be $87.5 \%$ level of accuracy. Test level accuracy $100 \%$ when tomatoes images shoot from side of tomatoes and $62.5 \%$ from side of tomatoes when images was repairing. When images not repairing level of accuracy $81 \%$ from top and $12.5 \%$ from top of tomatoes. The improving image can be increase the level of accuracy of classification level of ripening tomatoes.

\section{REFERENCES}

[1] Camelo, Andres F.Lopez and Perla A Gomez. 2004. Comparison of color indexes for tomato ripening. Horticultura Brasileira, Brasilia, v.22, n.3, p.534-537, jul-set 2004

[2] Irmansyah. 2009. Pemutuan Belimbing Berdasarkan Warna dan Rasa dengan Pengolahan Citra dan Logika Fuzzy. Tesis Sekolah Pasca Sarjana Institut Pertanian Bogor

[3] Noor, M.Helmy dan Moch. Hariadi. 2009. Image Cluster Berdasarkan Warna untuk Identifikasi Kematangan Buah Tomat dengan Metode Valley Tracing. Seminar Nasional Informatika 2009. ISSN 19792324

[4] Noviyanto, Ary. 2009. Klasifikasi Tingkat Kematangan Varietas Tomat Merah dengan Metode Perbandingan Kadar Warna. Ilmu Komputer, Fakultas MIPA, Universitas Gadjah Mada 
[5] Rizali,Yusuf. 2007. Pengembangan Algoritma Image Processing Untuk Menentukan Tingkat Kematangan Buah Tomat Segar. Departemen Teknik Pertanian Fakultas Teknologi Pertanian Institut Pertanian Bogor

[6] Satzinger, Jhon, Robert B. Jackson and Stephen D. Burd. 2009. System Analysis and Design In Changing World, Fifth Edition.. Thomson Course Tech., Canada 